\title{
RESEARCH
}

\section{VALIDATION OF THE TURKISH VERSION OF THE WHOQOL-AGE AND A PROPOSED ALTERNATIVE SCALE STRUCTURE}

Turkish Journal of Geriatrics

DOI: $10.31086 /$ tigeri.2020.150

2020; 23(2): 157-168

\section{- Cemil ÖZCAN ${ }^{1}$ (D) \\ - Erhan ESER ${ }^{1}$ iD}

CORRESPONDANCE

\section{Erhan ESER}

Manisa Celal Bayar University, School of

Medicine, Dept. Public Health, Manisa, TURKEY

Phone: +905324860677

e-mail: erhanese@gmail.com

Received: March 17, 2020

Accepted: May 02, 2020

${ }^{1}$ Manisa Celal Bayar University, School of Medicine, Dept. Public Health, Manisa, TURKEY

\section{Abstract}

Purpose: The WHOQOL-AGE is a combination of the EUROHIS-QOL.8 and the short version of the WHOQOL-OLD. The aim of the present study is to explore the psychometric properties of the Turkish version of the WHOQOL-AGE in terms of its validity and reliability.

Methods: Internal consistency, item-total correlations, and item success were analyzed taking the original structure into account. The validity tests consisted of construct validity and criterion validity analyses. The original scale structure was compared with a proposed new scale structure, comprised of two domains and based on the exploratory and confirmatory factor analysis, in terms of goodnessof-fit measures.

Results: The mean age of the sample population $(n=550)$ was $73.09 \pm 6.77$, and $58.9 \%$ were female. Skewness and kurtosis were both within accepted limits $(<1.0)$ and the floor and ceiling percentages also showed good measuring capacity $(<10 \%)$. The Cronbach alpha value was 0.90 for domain 1 and 0.86 for domain 2 . The goodness-of-fit analysis results for the original scale structure and the new scale structure, respectively, were comparative fit index $=0.89$ and 0.83 , Tucker Levis index $=0.87$ and 0.81 , and root mean square error of approximation (RMSEA) $=0.12$ and 0.073 .

Conclusion: The WHOQOL-AGE.TR is moderately compatible with the original scale structure. The EFA revealed a new scale structure: the domain 1 ('satisfaction with physical and mental health and well-being' domain) includes items 1-5, 9 and 10 , and the domain 2 ('satisfaction with economic and social well-being'domain) includes items 6-8 and 11-13.

Keywords: Quality of life; Aged; Psychometrics. 


\section{INTRODUCTION}

Quality of life (Q०L) for the elderly is of increasing importance as the frequency of chronic conditions grows worldwide, so health professionals need to implement QoL into their clinic practice for older adults. Therefore, there is a need for age-specific generic QoL scales evaluating quality of life for the older adults ( $\geq 65$ years of age). The World Health Organization Quality of Life Assessment (WHOQOL) is a tool for the evaluation of $\mathrm{CoL}$ in adults, and it has been developed into long (the WHOQOL-100), intermediate (the 26-item WHOQOL-BREF) (1), and short (the 8-item EUROHIS-QOL 8) (2) versions. The WHOQOL group, including the Turkish field center, also developed a supplementary module of the WHOQOL for older adults called WHOQOL-OLD (3), which has widely been used for geriatric and public health research. All of these instruments have been adapted for the Turkish population $(4,5)$. QoL experts recommend using the generic and population/condition-specific QoL instruments to assess $\mathrm{QoL}$ in all population groups. The only validated generic QoL instrument for the elderly in Turkey is the 24-item WHOQOL-OLD. As a result, when using a combination of these QoL tools for elderly patients, a long battery of items has to be applied, which is time-consuming for the professionals and difficult for the older patients to concentrate on. Fang et al. (6) developed three short versions of the WHOQOL-OLD, each consisting of six different WHOQOL-OLD items. The psychometric properties of the Turkish versions of these three short WHOQOL-OLD tools has been presented elsewhere with questionable psychometric results that might be attributed to the item on death and dying (7). Consistent with the Turkish psychometric results, in order to have a brief $\mathrm{QoL}$ tool for aging populations, the developers of WHOQOL-AGE dropped the death and dying item and combined the first short version of the WHOQOL-OLD with the EUROHIS-QOL 8 to create a new 13-item QoL instrument for the elderly, WHOQOL-AGE, in a project titled Collaborative Research on Ageing in Europe (COURAGE in Europe) (8). Despite recommendations that both a generic and an agespecific instrument be used for outcomes research, the 24-item WHOQOL-OLD has been frequently used in Turkish studies without combining it with any generic version (WHOQOL-100 or WHOQOLBREF), mainly to avoid using long instruments in geriatric research. The aim of the present study is to explore the psychometric properties of the Turkish version of the WHOQOL-AGE in terms of its validity and reliability.

\section{MATERIALS AND METHODS}

\section{Study sample}

The study sample consisted of 550 older adults recruited from two districts of Manisa Province to include both an urban and a rural population. The sample size was calculated with $95 \%$ confidence, $50 \%$ unknown event percentage, and 5\% precision. The urban and rural samples were randomly selected from among the urban districts $(n=1867)$ and rural districts $(n=1463)$ of the province by using a multistage sampling method using the records of the district family health centers.

\section{Measures}

The suggested items of the WHOQOL-AGE were taken from the already translated and validated Turkish versions of the EUROHIS-QOL 8 and the short version of the WHOQOL-OLD. The WHOQOL-OLD short (4) was combined with the EUROHIS-QOL 8 (7). With the item related to death and dying in the short WHOQOL-OLD excluded and a 13-item WHOQOL-AGE-TR was created, as suggested during the development of the original WHOQOL-AGE. So the WHOQOL-AGE 13 item scale structure is composed of EUROHIS-QOL (the first 8 items) and WHOQOL-OLD short items.

All participants completed the Katz Index of Independence in Activities of Daily Living (Katz ADL index) to assess their level of physical independence. The Katz ADL index measures 
independence in the six activities of bathing, dressing, toileting, transferring, continence, and feeding. For all six activities together, the possible score range for the Katz ADL index is 0-6 (9). Additionally, all participants answered questions about the presence of any chronic conditions or disabilities and their socio-demographics.

\section{Psychometric analyses}

The reliability and validity analyses were completed following the descriptive and item distribution analyses.

Both exploratory and confirmatory approaches were employed during the reliability analyses and factor analyses. The exploratory approach was used to probe the possible change in structure of the WHOQOL-AGE, and the confirmatory approach was used to test the predefined and suggested item/domain structure of the original instrument.

\subsection{Distributional properties}

The distribution properties of each item and predefined domain of the WHOQOL-AGE were determined through skewness and kurtosis analyses, and the measurement capacity of each domain was evaluated through floor and ceiling effects. The limit values were accepted as 1.0 for skewness, 2.0 for kurtosis, and 15\% for the floor and ceiling effects (10).

\subsection{Reliability analyses}

Internal consistency, item-total correlations, and item success (based on the item-domain correlation results) were analyzed with a confirmatory approach by considering the original structure of the WHOQOL-AGE.

Cronbach's alpha coefficients were calculated to assess the internal consistency of the overall scale and domains of the instrument. The expected minimum satisfactory value for alpha was around 0.7. Alpha values for the case of 'if item deleted' were also calculated in order to show the contribution of each item to the scale variances.
For any item that makes a positive contribution to its own domain, the alpha value is expected to be lower than the global alpha value when the problematic- item is removed from the analysis.

Item-total correlations assume that an item should have a correlation coefficient at least 0.3 with the domain it belongs to. The term 'item success' refers to the percentage of items that have higher correlations with their domain. In other words, all items are expected to have significantly higher correlation coefficients with the domain they belonged to than with the other domain.

\subsection{Validity analyses}

The validity analyses consisted of construct validity and criterion validity analyses. Factor, known groups, and convergent validity analyses were employed to examine the construct validity of the scale.

\subsubsection{Factor analyses}

Both exploratory (EFA) and confirmatory factor analyses (CFA) were done to test the construct validity of the Turkish WHOQOL-AGE-TR. The EFA was run using principal components analyses with oblique (direct oblimin) rotation. Satisfactory fit of the Turkish version to the original WHOQOLAGE scale structure was tested using several goodness-of-fit indices generated by CFA, such as the comparative fit index (CFI), root mean square error of approximation (RMSEA), and chi-square. The cut-off values of good fit for these indices are $>0.90$ for $\mathrm{CFI},<0.08$ for RMSEA, and $<2.0$ for the ratio of chi-square to degrees of freedom $\left(\chi^{2} / \mathrm{df}\right)$ (11). The $\chi^{2} / \mathrm{df}$ ratio was preferred since chi-square statistics are sensitive to sample size.

\subsubsection{Known groups validity}

The known groups validity of the WHOQOLAGE-TR was tested using the hypotheses that advanced age, poor education, low social class, chronic illness, poor living conditions, inadequate social support, and verbal and/or physical abuse of the elderly can decrease WHOQOL-AGE scores. 


\subsubsection{Convergent/discriminant validity}

The Katz ADL index scores were divided into three categories as 'totally dependent', 'partially dependent', and 'independent', and the mean domain scores of these categories were compared.

\subsubsection{Criterion validity}

Additionally, a criterion validity analysis was carried out by running a multiple linear regression using the general QoL item of the WHOQOL-AGE (item 1) as a reference dependent variable and the domains as independent variables.

A Students' t-test was run for the comparison of two independent continuous variables, and a oneway analysis of variance (ANOVA) was used for three or more independent continuous variables, where the parametric test requirements were satisfied and Cohen's effect size (ES) was used to distinguish the effects of different variables on the WHOQOL-AGE scores (12).

Parametric and non-parametric statistics were used to compare the means where appropriate. Post hoc comparisons were done using the Tukey's B. Spearman's correlation was used for the comparison of the two discrete numeric variables. The statistical packages used were SPSS version 23.0 and Lisrel 8.05. The acceptable type 1 error was considered as less than 0.05 in the analyses.

\section{Ethical issues}

The study was approved by the Ethics committee of Manisa Celal Bayar University (July 10, 2019/Ref 20.478.486).

\section{RESULTS}

The mean age of the sample population was $73.09 \pm 6.77 ; 58.9 \%$ were female; $31.3 \%$ has no education; $22.4 \%$ had inadequate income, $29.1 \%$ were physically dependent to some extent, $34.0 \%$ was living alone; and $77.9 \%$ suffered from at least one chronic illness; $21.2 \%$ has ever been faced a kind of abuse; $17.2 \%$ reported poor relationships with friends or family members.

\section{Item and reliability analyses}

The item score distributions assessed by skewness and kurtosis were all in accepted limits and floor and ceiling percentages also indicated a good measuring capacity not exceeding 10\%. Itemdomain correlations were all above 0.30 and each of the items had a higher correlation coefficient with the domain it belonged to compared to its correlation with the other domain. One exception is the item 9, which showed high correlations with both domains of the WHOQOL-AGE. In the urban sample, items 9 and 10 correlated higher with domain 1 than domain 2, which they belong to according to the original scale structure. The mean inter-item correlation for the WHOQOLAGE-TR items was 0.54 for item 9 and 0.40 for item 13 , with pairwise correlations ranging from 0.30 to 0.73 . The internal consistencies of both domains are satisfactory, with alpha values for domain 1 and domain 2 at 0.90 and 0.86 , respectively (Table 1). None of the 13 items indicate any problem in the 'if item deleted/removed' analyses for either the urban or rural samples. This confirms that all of the items contribute to the variances of the domains they belong to.

The domain and overall scale scores were similar $(P>0.05)$ between the urban and rural study samples. The scores for domain 1 were $66.07 \pm 14.35$ and $64.63 \pm 13.13$ for the urban and rural samples, respectively. The scores for domain 2 were $63.34 \pm 13.40$ and $61.51 \pm 13.39$ for the urban and rural samples, respectively. The overall scale scores were $64.70 \pm 13.22$ and $63.07 \pm 12.72$ for the urban and rural samples, respectively.

\section{Construct validity analyses}

The construct validity of the Turkish version of the WHOQOL-AGE was tested using known groups validity, convergent/divergent validity, and factor analyses. Both exploratory and confirmatory approaches were employed for convergent/ divergent validity and factor analyses.

The known groups validity results for the 
Table 1. Item distributions, item success, measurement capacity and the internal consistency of the origianal scale structure of the Turkish WHOQOL-AGE.

\begin{tabular}{|c|c|c|c|c|c|c|c|c|}
\hline Item & $\begin{array}{r}\text { Mean } \\
(\text { SD) }\end{array}$ & Skewness & Kurtosis & $\begin{array}{r}\text { Floor } \\
(\%)\end{array}$ & $\begin{array}{r}\text { Ceiling } \\
(\%)\end{array}$ & $\begin{array}{r}\text { Correlation } \\
\text { with } \\
\text { Dom.1** }\end{array}$ & $\begin{array}{r}\text { Correlation } \\
\text { with } \\
\text { Dom.2** }\end{array}$ & $\begin{array}{r}\text { If item } \\
\text { deleted } \\
\text { Cronbach's } \\
\text { Alpha*** }\end{array}$ \\
\hline 2 & $3.22(0.97)$ & -0.20 & -0.42 & 4.0 & 8.0 & 0.74 & 0.57 & 0.89 \\
\hline 3 & $3.03(0.92)$ & -0.20 & -0.19 & 5.6 & 3.8 & 0.75 & 0.61 & 0.88 \\
\hline 4 & $3.26(0.93)$ & -0.43 & -0.12 & 4.2 & 5.6 & 0.81 & 0.63 & 0.88 \\
\hline 5 & $3.19(0.99)$ & -0.35 & -0.42 & 5.5 & 6.6 & 0.79 & 0.65 & 0.88 \\
\hline 6 & $3.46(0.83)$ & -0.43 & -0.01 & 1.3 & 7.1 & 0.70 & 0.59 & 0.89 \\
\hline 7 & $3.47(0.89)$ & -0.38 & -0.15 & 1.6 & 9.5 & 0.66 & 0.57 & 0.90 \\
\hline 8 & $3.15(0.94)$ & -0.10 & -0.40 & 3.5 & 6.4 & 0.73 & 0.60 & 0.89 \\
\hline$(1)^{\star}$ & $3.16(0.86)$ & -0.32 & 0.21 & 4.0 & 4.0 & 0.76 & 0.73 & 0.88 \\
\hline 9 & $3.10(0.96)$ & -0.18 & -0.26 & 5.6 & 5.8 & 0.71 & 0.70 & 0.82 \\
\hline 10 & $3.00(0.90)$ & -0.05 & -0.40 & 3.8 & 3.5 & 0.66 & 0.74 & 0.82 \\
\hline 11 & $2.99(0.91)$ & -0.06 & -0.38 & 4.5 & 3.6 & 0.67 & 0.77 & 0.82 \\
\hline 12 & $3.10(0.90)$ & -0.07 & -0.10 & 3.6 & 6.7 & 0.53 & 0.74 & 0.86 \\
\hline 13 & $3.23(0.88)$ & -0.14 & -0.33 & 2.0 & 5.6 & 0.53 & 0.73 & 0.86 \\
\hline
\end{tabular}

* Item 1 loads on both of the 1 st and the 2 nd domains of the original scale structure;

** Spearman's Rho;

*** Cronbach's Alpha values for the Domain $1=0.90$ and Domain 2=0.86

WHOQOL-AGE-TR are presented in table 2 according to the original scale structure. The WHOQOL-AGE-TR domain scores and overall scores could be distinguished by all of the subgroups of the known groups variables.

The EFA, run independently using varimax and direct oblimin rotations, revealed a somewhat different domain structure compared to that of the original scale structure proposed by Brown et al. (13) (Table 3). The Kaiser-Meyer-Olkin value was $0.94(>0.5)$ and Bartlett's test of sphericity was significant $(p<0.001)$ for all of the factor analyses. The adjusted coefficient of determination (R2) was 62.5 .

In the varimax rotation, even if the unstable items 6,8,10, and 11 were left aside, items 7 and
9 were in unexpected domains in regard to the original structure. In contrast, the direct oblimin rotation stabilized the item loadings of the item 6 and item 8 which were unstable items in the varimax rotation, forming domain 1 consisting of items $1-5,9$, and 10 and domain 2 consisting of items 6-8,12, and 13. Only item 11 was found to be unstable in the oblimin rotation. The items 7 and 9 were loaded in unexpected domains, consistently in both Varimax and Oblimin rotation solutions. Eventually, the EFA revealed a two-domain structure in the Turkish version with different item compositions than the original scale structure; domain 1 includes items 1-5,9, and 10, which relate to 'satisfaction with physical and mental health and well-being', and domain 2 includes items $6-8$ and 11-13, which relate to 'satisfaction with economic 
Table 2. Known groups validity analyses for the Turkish version of the WHOQOL-AGE***.

\begin{tabular}{|c|c|c|c|c|}
\hline & & Domain 1 & Domain 2 & Overall Score \\
\hline \multirow{3}{*}{ Gender } & Male & $66.7 \pm 14.2$ & $64.5 \pm 13.0$ & $65.6 \pm 12.9$ \\
\hline & Female & $64.5 \pm 13.5$ & $61.1 \pm 13.5$ & $62.8 \pm 13.0$ \\
\hline & $\mathrm{p}\left(\mathrm{ES}^{\star}\right)$ & $0.068(0.16)$ & $0.004(0.24)$ & $0.014(0.22)$ \\
\hline \multirow{3}{*}{ Marital st. } & Married & $68.1 \pm 12.5$ & $64.9 \pm 12.1$ & $66.5 \pm 11.7$ \\
\hline & Single & $61.7 \pm 14.7$ & $59.2 \pm 14.3$ & $60.4 \pm 13.9$ \\
\hline & $\mathrm{p}\left(\mathrm{ES}^{\star}\right)$ & $<0.001(0.48)$ & $<0.001(0.43)$ & $<0.001(0.47)$ \\
\hline \multirow{4}{*}{ Education } & Illiterate(a) & $60.9 \pm 14.2$ & $58.1 \pm 13.5$ & $59.5 \pm 13.2$ \\
\hline & Primary(b) & $64.4 \pm 13.7$ & $60.9 \pm 12.8$ & $62.6 \pm 12.6$ \\
\hline & $\begin{array}{r}\text { Secondary and } \\
\text { over(c) }\end{array}$ & $69.3 \pm 12.5$ & $66.6 \pm 12.5$ & $67.9 \pm 11.9$ \\
\hline & $\begin{array}{r}\text { p, Post hoc**, } \\
\left(\text { ES }^{\star}\right) \\
\end{array}$ & $\begin{array}{r}<0.001, a<b<c, \\
(0.51)\end{array}$ & $\begin{array}{r}<0.001, \mathrm{a}<(\mathrm{b}=\mathrm{c}), \\
(0.50)\end{array}$ & $\begin{array}{r}<0.001, a<b<c, \\
(0.52)\end{array}$ \\
\hline \multirow{3}{*}{ Chronic Illness } & Present & $63.5 \pm 13.8$ & $61.0 \pm 12.9$ & $62.3 \pm 12.8$ \\
\hline & Absent & $72.4 \pm 13.4$ & $68.6 \pm 13.5$ & $70.5 \pm 11.9$ \\
\hline & $p\left(E S^{\star}\right)$ & $<0.001(0.64)$ & $<0.001(0.56)$ & $<0.001(0.63)$ \\
\hline \multirow{4}{*}{$\begin{array}{l}\text { Physical } \\
\text { dependency } \neq\end{array}$} & Totally dependent & $43.3 \pm 11.7$ & $44.4 \pm 11.9$ & $43.8 \pm 11.3$ \\
\hline & Partially dependent & $56.3 \pm 11.6$ & $54.1 \pm 11.1$ & $55.2 \pm 11.6$ \\
\hline & Independent & $69.8 \pm 11.9$ & $66.4 \pm 11.1$ & $68.1 \pm 11.3$ \\
\hline & Post hoc**. (ES*) & $\begin{array}{r}<0.001, \mathrm{a}<\mathrm{b}<\mathrm{c}, \\
(1.94)\end{array}$ & $\begin{array}{r}<0.001, a<b<c, \\
(1.59)\end{array}$ & $\begin{array}{r}<0.001, a<b<c, \\
(1.87)\end{array}$ \\
\hline \multirow{3}{*}{$\begin{array}{l}\text { Abuse } \\
\text { (physical- } \\
\text { psychological) }\end{array}$} & Never & $56.4 \pm 1.8$ & $52.6 \pm 12.3$ & $54.5 \pm 11.5$ \\
\hline & At least once & $66.8 \pm 12.6$ & $63.9 \pm 12.6$ & $65.4 \pm 12.1$ \\
\hline & $p\left(E S^{\star}\right)$ & $<0.001(0.86)$ & $<0.001(0.92)$ & $<0.001(0.93)$ \\
\hline
\end{tabular}

${ }^{\star}$ Cohen's Effect size (18); ${ }^{* *}$ Tukey B; ${ }^{* \star *}$ Original Scale structure; $\ddagger$ Assessed by Katz index

and social well-being'. Item 1, the overall QoL item of the WHOQOL-AGE-TR, which is almost equally loaded (unstable) in both domains in the varimax rotation, was decisively included (highly loaded) in domain 1 during the oblimin rotation (Table 3).

The comparison of the EFA results for the rural, urban, and overall data sets by direct oblimin rotation revealed that the rural and urban data sets showed invariance in items 6 and 11 (not shown here due to restricted number tables). Similar invariances for items 12 and 13 were reported from three different country sets in the COURAGE study (14), and these invariances were mainly attributed to socioeconomic variables. In addition to the socioeconomic differences between the rural and urban samples, sociocultural diversity may also contribute to these inconsistencies. For example, item 6, which is related to satisfaction with 
Table 3. Exploratory Factor Analysis results of the Turkish version of the WHOQOL-AGE by using two different rotation methods with Kaiser Normalization.

\begin{tabular}{|c|c|c|c|c|}
\hline \multirow[t]{2}{*}{ Items } & \multicolumn{2}{|c|}{ Varimax rotation } & \multicolumn{2}{|c|}{ Direct Oblimin rotation } \\
\hline & Dom.1 & Dom.2 & Dom.1 & Dom.2 \\
\hline Q1... overall quality of life & ,645 &, 458 & ,605 & ,260 \\
\hline Q2...satisfied with... senses overall? & ,736 & ,203 & 811 &,- 083 \\
\hline Q3...satisfied with your health? &, 837 &, 212 &, 929 &,- 115 \\
\hline Q4...satisfied with oneself? & ,738 &, 356 & ,755 & ,098 \\
\hline Q5...satisfied to perform daily living activities? &, 814 & ,305 &, 866 &, 005 \\
\hline Q6...satisfied with personal relationships? &, 424 &, 587 & ,290 &, 510 \\
\hline Q7...satisfied with ..living place (home)? &, 170 & 807 &,- 100 & ,882 \\
\hline Q8...satisfied with the way you use time &, 437 &, 596 &, 302 &, 515 \\
\hline Q9...enough energy for everyday life? & ,789 &, 307 &, 836 & ,018 \\
\hline Q10. control over the things he/she likes to do? &, 649 &, 437 & 617 &, 234 \\
\hline $\begin{array}{l}\text { Q11. satisfied with opportunities to continue } \\
\text { achieving in life }\end{array}$ &, 523 &, 596 &, 406 & ,477 \\
\hline Q12. enough money to meet needs? &, 167 & ,750 &,- 082 &, 816 \\
\hline Q13. satisfied with intimate relationships? & ,332 &, 579 & ,182 &, 540 \\
\hline Adjusted R2 & & & & \\
\hline
\end{tabular}

personal relationships and was originally included in domain 1 of the WHOQOL-AGE, was loaded in domain 2 ('satisfaction with economic and social well-being') for the rural sample and domain 1 ('satisfaction with physical and mental health and well-being') for the urban sample. Obviously, this item was comprehended in different ways by rural and urban older adults, but it loaded consistently in domain 2 in the overall dataset. Similarly, item 11 , which relates to satisfaction with opportunities to continue achieving in life, was loaded in domain 1 for the rural sample, in domain 2 for the urban dataset, and shared with both domains in the overall dataset. Nevertheless, since its loading is higher for domain 2 and it is conceptually closer to 'satisfaction with economic and social well-being', item 11 was assigned to domain 2 of the Turkish version.

According to the original scale structure, items 2-8 formed domain 1, items 9-13 formed domain 2 , and item 1 was shared by both domains. Based on this original structure, the goodness-of-fit statistics of the WHOQOL-AGE-TR generated by CFA were $\mathrm{CFI}=0.89$, Tucker Levis index $(\mathrm{TLI})=0.87$, RMSEA $=0.12$, and $\chi 2 / d f=8.26$. In comparison, the goodness-of-fit statistics of the newly proposed WHOQOL-AGE scale structure based on the EFA 
were $\mathrm{CFI}=0.83, \mathrm{TLI}=0.81, \mathrm{RMSEA}=0.073$, and $\chi 2$ / $d f=8.26$.

Convergent validity results are presented in Table 4. The Katz ADL index physical dependency categories were sensitive to the domain scores of both the original scale structure and the proposed alternative scale structure $(P<0.001)$. On the other hand, the difference between the correlation coefficients of the Katz ADL index score and the two domain scores of the proposed alternative structure (0.58 vs. 0.41$)$ was greater than with the original scale structure (0.51 vs 0.47$)$, indicating there is better convergence between the domains of the alternative scale structure proposed in this paper.

The criterion validity of the WHOQOL-AGE-TR was tested by regressions of the general QoL item (item 1) against the individual items of WHOQOLAGE (table 5). The R2 values for both domains are acceptable. Except items 6 and 10, all the other items have a meaningful relationship with reference item 1. All of the Variance Inflating Factor (VIF) values are in acceptable limits rejecting any co-linear relationships between items.

\section{DISCUSSION}

WHOQOL-AGE has just recently developed as a hybrid instrument of two QoL scales: EUROHISQOL 8 (15) and one of the three short versions of the WHOQOL-OLD $(16,17)$. Both of the mother tools (i.e. WHOQOL-BREF and WHOQOL-OLD) consist of four and six domains, respectively. Although the invariance of the WHOQOL-AGE among three different populations was presented (18), there is a need to examine the scale structure of the WHOQOL-AGE for different cultures and populations. Thus, this research tested the goodness of fit of the Turkish WHOQOL-AGE-TR against the original structure using exploratory and confirmatory approaches. The main reason for using the exploratory approach is the different scale structures of the EUROHIS-QOL 8 between the Turkish validation study (4) and some other country-specific data (Romania, Slovakia, and Israel) in a global EUROHIS study (15). In the Turkish validation study and especially in the Romanian sample of the global EUROHIS study, the EUROHIS-QOL 8 revealed a two-domain structure. Additionally, the developers of the WHOQOLAGE proposed two different item compositions for the scale. Caballero et al. (8) suggested that item 1 be a shared item between the two domains

Table 4. Convergent validity of both the original scale structure and alternative scale structure by using daily living activities assessed by KATZ index.

\begin{tabular}{|c|c|c|c|c|c|c|}
\hline & & $\begin{array}{r}\text { Independent } \\
(n=390)(a)\end{array}$ & $\begin{array}{r}\text { Partially } \\
\text { dependent } \\
(n=141)(b)\end{array}$ & $\begin{array}{r}\text { Totally } \\
\text { dependent } \\
(n=19)(c)\end{array}$ & $\begin{array}{r}P^{\star *} \\
\text { (post hoc }\end{array}$ & $\begin{array}{r}\text { KATZ } \\
\text { index score } \\
\text { (Spearman's } \\
\text { Rho) }\end{array}$ \\
\hline \multirow[t]{2}{*}{$\begin{array}{l}\text { Developer's } \\
\text { (Original) scale } \\
\text { structure }\end{array}$} & Domain 1 & $69.77 \pm$ & $56.32 \pm$ & $43.32 \pm$ & $\begin{array}{l}<0.001 \\
a>b>c\end{array}$ & 0.51 \\
\hline & Domain 2 & $66.742 \pm$ & $54.13 \pm$ & $44.36 \pm$ & $\begin{array}{l}<0.001 \\
a>b>c\end{array}$ & 0.47 \\
\hline \multirow[t]{2}{*}{$\begin{array}{l}\text { Our alternative } \\
\text { scale structure* }\end{array}$} & Domain 1 & $68.03 \pm$ & $51.04 \pm$ & $36.28 \pm$ & $\begin{array}{l}<0.001 \\
a>b>c\end{array}$ & 0.58 \\
\hline & Domain 2 & $68.41 \pm$ & $58.16 \pm$ & $48.90 \pm$ & $\begin{array}{l}<0.001 \\
a>b>c\end{array}$ & 0.41 \\
\hline
\end{tabular}

* Domain 1: Satisfaction with physical and mental health and well-being; Domain 2: Satisfaction with economical and social well-being ; **Kruskall Wallis ANOVA ${ }^{* * \star M a n n}$ Whitney $\cup$ (pairwise comparisons, type 1 error was considered as $<0.015$ ) 
Table 5. The regressions of the general Quality of Life item $(q 1)^{\star}$ against the remaining items, for each of the domains of the WHOQOL-AGE (Multiple linear regression analyses for the original scale structure).

\begin{tabular}{|c|c|c|c|}
\hline Item / Domain & Standardized Beta & $p^{* *}$ & VIF** \\
\hline \multicolumn{4}{|l|}{ Items of the Domain 1 (model 1) } \\
\hline Q2...satisfied with... senses overall? & ,209 &, 000 & 1,777 \\
\hline Q3. ..satisfied with your health? &, 130 &, 006 & 2,694 \\
\hline Q4. ..satisfied with oneself? &, 176 &, 000 & 2,707 \\
\hline Q5. ..satisfied to perform daily living activities? &, 131 &, 005 & 2,673 \\
\hline Q6. ..satisfied with personal relationships? & ,070 &, 064 & 1,710 \\
\hline Q7. ..satisfied with ..living place (home)? &, 117 & 001 & 1,550 \\
\hline Q8. ..satisfied with the way you use time &, 132 &, 001 & 1,736 \\
\hline R2 $=0.55 ;$ Constant & - &, 025 & - \\
\hline \multicolumn{4}{|l|}{ Items of the Domain 2 (model 2) } \\
\hline Q9. ..enough energy for everyday life? & 224 &, 000 & 2,042 \\
\hline Q10. control over the thing he/she likes to do? &, 069 & 176 & 2,593 \\
\hline Q11. satisfied with opportunities to continue achieving in life & ,306 &, 000 & 2,439 \\
\hline Q12. enough money to meet needs? &, 138 &, 000 & 1,476 \\
\hline Q13. satisfied with intimate relationships? & 101 &, 008 & 1,393 \\
\hline R2 $=0.45 ;$ Constant & - &, 000 & - \\
\hline
\end{tabular}

${ }^{*}$ q1 (general quality of life item) as dependent variable; **VIF: Variance Inflating factor as an indicator of colinearity.

whereas Santos et al. (18) classified item 1 only in domain 1 of the WHOQL-AGE.

The distribution parameters did not indicate any problems for any of the items. Skewness and kurtosis are in acceptable limits for all items of the WHOQOL-AGE. The mean WHOQOL-AGE score of this study sample was around 64 whereas the results of a COURAGE study presented by Raggi et al. (19) gave overall higher mean WHOQOLAGE scores (Finnish 78, Polish 70, and Spanish 74). These score differences can easily be attributable to the mean age of the study samples. The mean age of this study sample was 73 while that of the COURAGE study had a much younger mean age range of 45-57.

Reliability analyses of the original scale structure were also found to be within acceptable limits and consistent with the original development papers $(8,18)$. The Cronbach's alpha values for both domains were above 0.70 , and the 'if item deleted' alpha values indicated that all items positively contributed to their domains. In terms of item success, all items except item 9 had significantly higher correlation coefficients with the domain they belonged to than with the other domains. Item success was about 92\% (12/13), confirming the adequacy of the internal consistency.

The known groups validity analyses revealed satisfactory results for the original scale structure. As expected, the existence of any chronic illness, physical dependency, or physical/psychological abuse revealed quite high ES values. The 
discriminating effects of level of education, health, physical/psychological well-being, social support, abuse, and dependency were all confirmed by the previous QoL literature on the elderly $(14,20,21$, 22).

The EFA was run by principal components analyses using an oblique (direct oblimin) rotation since the correlation coefficient between the two suggested domains of the WHOQOL-AGE was 0.82 , which a number of statisticians have suggested is a high correlation. Due to the same rationale (i.e. correlated domains), the $\mathrm{WHOQOL}$ AGE developers also used a geomin rotation, which is designed as an oblique rotation $(23,24)$. Hence, direct oblimin rotation stabilized the item loadings of the varimax rotation, allowing for the proposal of an alternative scale structure. The two-domain solution of the WHOQOL-AGE-TR explained $62.5 \%$ of the variance, which is very close to the $65.0 \%$ of the development study (8).

Based on the EFA of the Turkish data, the CFA results are somewhat contradictory between the original scale structure and the proposed alternative scale structure, so the goodnessof-fit statistics that were generated for both the original and the proposed scale structures need to be reviewed. As conventionally suggested, three goodness-of-fit indices (CFI, TLI, RMSEA) and a badness-of-fit measure (chi-square) were used in this study. Beginning with chi-square, as the original research did (8), this study also could not reach an acceptable $\chi^{2} / \mathrm{df}$ figure $(<2.0)$ since this measure is sensitive to sample size. We found similar CFI and TLI figures, both less than 0.90, for the original scale structure $(8,18,19,25)$ and the proposed alternative scale structure. However, the RMSEA values are quite different between these two scale structures. The RMSEA value was 0.12 for the original scale structure whereas it was 0.073 for the alternative scale structure. The CFI statistic assumes that all latent variables are uncorrelated, but the latent variables are correlated in this study. Therefore, the RMSEA is more reliable than the
CFI for this study, which means that the alternative scale structure may be better than the original scale structure from the COURAGE study.

The Katz ADL index was used to test the convergent validity of the WHOQOL-AGE based on the hypothesis that high physical dependency (as assessed by the KATZ ADL index) is expected to correlate with physical wellness items or domains. The results showed that the difference between the correlation coefficients of Katz ADL index and the domain 1 and domain 2 scores are greater for the alternative scale structure $(0.58$ $-0.41=0.17)$ than the original structure $(0.51-$ $0.47=0.04$ ) (Table 6). The fact that domain 1 of the alternative structure is composed of more concrete health and well-being items may explain the higher correlation coefficient between the Katz ADL index score and domain 1 ('satisfaction with physical and mental health and well-being') score and the lower correlation coefficient between the Katz ADL index score and domain 2 ('satisfaction with economic and social well-being') score of the alternative scale structure. This indicates a good convergence and divergence of the alternative structure of the WHOQOL-AGE-TR.

\section{CONCLUSION}

The new alternative scale structure proposed in this paper is moderately compatible with the original scale structure of the WHOQOL-AGE proposed by the developers of the instrument. An alternative two-domain scale structure is suggested in this paper with a better RMSEA value than the original structure. The two domains of WHOQOL-AGE generated in this study are called 'satisfaction with physical and mental health and well-being' and 'satisfaction with economic and social well-being'. Further studies are needed to test the original and alternative scale structures of the WHOQOL-AGE in different populations and cultures. 


\section{REFERENCES}

1. The WHOOOL Group. Development of the World Health Organization WHOQOL-BREF quality of life assessment. Psychol Med 1998; 28(3):551-58. (PMID: 9626712)

2. Schmidt S, Mühlan H, Power M. The EUROHIS-OOL 8-item index: psychometric results of a cross-cultural field study. Eur J Public Health 2006;16(4): 420-28. (PMID: 16141303)

3. Power M, Quinn K, Schmidt S, WHOQOL-OLD Group. Development of the WHOQOL-old module. Qual Life Res 2005;14(10):2197-214. (PMID: 16328900)

4. Eser E, Lağarlı T, Baydur H. et al. Psychometric properties of The Turkish version of the EUROHIS$\operatorname{Tr}$ (WHOQOL-8-Tr) in a Turkish population. Turkish Journal of Public Health 2010;8(3):136-152. [Internet] Available from: https://dergipark.org.tr/tr/pub/tjph/ issue/16578/173107. Accessed: 11.03.2020.

5. Eser S, Saatli G, Eser E, Baydur H, Fidaner C. The Reliability and Validity of the Turkish Version of the World Health Organization Quality of Life InstrumentOlder Adults Module (WHOQOL-OLD). Turkish Journal of Psychiatry 2010; 21(1): 37-48. (PMID: 20204903)

6. Fang J, Power M, Lin Y, Zhang J, Hao Y, Chatterji S. Development of short versions for the WHOQOLOLD module. Gerontologist 2012; 52(1):66-78. (PMID: 22021402)

7. Eser E, Eser S. Testing psychometric properties of the three short versions for the WHOOOL-OLD Module in Turkish national data pool. Preceedings 25th ISOQOL Annual Conference. 24-27 October 2018, Dublin, Ireland. [Internet] Available from: http://www. isoqol.org/UserFiles/AC18/AC18_FinalProgram_ web.pdf. Accessed: 11.03.2020.

8. Caballero FF, Miret M, Power $\mathrm{M}$ et al. Validation of an instrument to evaluate quality of life in the aging population: WHOQOL-AGE. Health Qual Life Outcome 2013; 23(11):177. (PMID:24152691)

9. Katz S, Down TD, Cash HR, \& Grotz RC. Progress in the development of the index of ADL. The Gerontologist 1970; 10(1): 20-30. (PMID: 5420677)

10. Andresen EM. Criteria for assessing the tools of disability outcomes research. Archives of Physical Medicine and Rehabilitation 2000: 81:15-20. (PMID: 11128900)

11. Hu LT, Bentler PM. Cut off criteria for fit indices in covariance structure analysis: conventional criteria versus new alternatives. Struct Equ Model 1999; 6:1-

\section{Doi: 10.1080}

12. Cohen J. Statistical Power Analysis for the Behavioural Sciences. 2nd ed. Lawrence Erlbaum, New York: 1988,p20.

13. Brown JD. Statistics Corner. Questions and answers about language testing statistics: Choosing the Right Type of Rotation in PCA and EFA. Shiken: JALT Testing \& Evaluation SIG Newsletter 2009; 13(3): 2025. [Internet] Available from: http://hosted.jalt.org/ test/bro_31.htm . Accessed: 11.03.2020.

14. Adamczyk BT, · Galas A, - Zawisza K, et al. Genderrelated differences in the multi-pathway effect of social determinants on quality of life in older agethe COURAGE in Europe project. Qual Life Res 2017; 26:1865-1878. (PMID: 28258420)

15. Schmidt S, Mühlan H, Power M. The EUROHIS-OOL 8-item index: psychometric results of a cross-cultural field study. European Journal of Public Health 2006; 16(4): 420-428. (PMID:16141303)

16. Power M, Quinn K, Schmidt S. WHOQOL-OLD Group. Development of the WHOOOL-old module. Qual Life Res. 2005; 14(10):2197-214. (PMID:16328900)

17. Fang J, Power M, Lin Y, Zhang J, Hao Y, Chatterji S. Development of short versions for the WHOQOLOLD module. Gerontologist 2012; 52(1):66-78. (PMID: 22021402)

18. Santos D, Abad FJ, Miret M, et al. Measurement invariance of the WHOQOL-AGE questionnaire across three European countries. Qual Life Res 2018; 27:1015-1025. (PMID: 29143905)

19. Raggi A, Corso B, Minicuci N, Quintas R, Sattin D, De Torres L. Determinants of Quality of Life in Ageing Populations: Results from a Cross-Sectional Study in Finland, Poland and Spain. PLoS ONE. 2016 ; 11(7):117. (PMID: 27434374)

20. Garin N, Olaya B, Moneta MV, et al. Impact of Multimorbidity on Disability and Quality of Life in the Spanish Older Population. PLoS ONE 2014; 9(11): 1-12. e111498. (PMID: 25375890)

21. Lobo Ade J, Santos L, Gomes S. Level of dependency and quality of life of elderly. Rev Bras Enferm 2014; 67(6):913-9. (PMID: 25590881)

22. Lara E, Koyanagi A, Caballero F, et al. Cognitive reserve is associated with quality of life: A populationbased study. Experimental Gerontology 2017; 87: 67-73. (PMID: 27825839)

23. Celimli Aksoy S. "A Comparison of Geomin 
versus Target Rotation Criteria in Exploratory Factor Analysis with Correlated Factors and Large and Complex Pattern Matrices". Open Access Dissertations. 1941, 2017. [Internet] Available from:https://scholarlyrepository.miami.edu/oa_ dissertations/1941. Accessed: 09.03.2020.

24. Tabachnick BG, \& Fidell, LS. (Eds). Using multivariate statistics. 5th edition, Upper Saddle River, NJ: Pearson Allyn \& Bacon, Boston, MA, USA 2007, pp 646-647.

25. Zawisza K, Gałaś S, Adamczyk BT. Validation of the Polish version of the WHOQOL-AGE scale in older population. Gerontologia Polska 2016; 24: 7-16. [Internet] Available from: http://gerontologia.org. pl/wp-content/uploads/2016/05/GerontologiaPolska_1_2016.pdf. Accessed: 11.03.2020. 